\title{
Modeling Thermal Radiation in Open Liquid Pool Fires
}

\author{
K. C. ADIGA and D. E. RAMAKER \\ Chemistry Department \\ George Washington University \\ Washington D.C. 20052, USA
}

\author{
P. A. TATEM and F. W. WILLIAMS \\ Chemistry Division \\ Naval Research Laboratory \\ Washington D.C. 20375-5000, USA
}

ABSTRACT

A non-isothermal, non-homogeneous approach has been developed for radiation analysis of moderate to large scale liquid pool fires, with a special emphasis on soot formation and the absorption and emission processes. The present field approach reveals the phenomenon of radiative energy blockage by the cold fuel and soot particles in the vicinity of the fuel bed, resulting in a variable heat flux distribution at the fuel surface. The convective contribution to the heat feedback at the fuel surface is found to decrease from 54 to $5 \%$ as the pool diameter increases from 15 to $50 \mathrm{~cm}$, while the radiative contribution proportionately increases. The estimated mass evaporation rate and the total radiative output from the flame agree closely with experiment.

\section{INTRODUCTION}

Current interests in the thermal radiation behavior of pool fires exists primarily because of its importance in controlling the mass burning rate and overall fire hazard of moderate to large scale pool fires [1]. In a sooting flame, radiation is strongly affected by the soot absorption process. In such flames, the maximum energy feedback has been postulated to come from the bottom $20-30 \%$ of the flame height [1]. The vicinity of the flame base comprises basically the cold fuel vapor and the soot particles. Hence a precise knowledge of the spatial distribution of the gaseous species, soot particles, and the temperature is necessary for a quantitative estimation of the flame radiation to the fuel surface.

The previous work on radiation analysis has been reported by de Ris [1], Modak [2], Markstein [3,4], and Brosmer and Tein [5]. These models were of varying degrees of complexity. For example, most of the previous models include the mean beam length approach combined with the uniform, isothermal, gray gas absorption approximation. However, the importance of non-gray, non-isothermal, and non-homogeneous effects in sooty fires of moderate scale has been shown by Buckius and Tein [6]. The recent studies by Brosmer and Tein [5] considered the radiative energy blockage by the cold fuel vapor at the vicinity of the burning fuel surface.

The objective of the present work is to carry out a comprehensive analysis of the thermal radiation problem in a sooting liquid fuel fire of practical interests, such as the kerosene type of hydrocarbon fuels. The approach involves an estimation of the velocity and various scalar quantities in the flame with a special emphasis on soot formation, the 
smoking tendency of the flame, and the thermal radiation from various parts of the flame both to the fuel source (feedback) and its surroundings. A four flux model is incorporated into the finite difference scheme of the main flame calculation. The model is developed with a concern for computational economy, and to provide a basic understanding of the physics, and the transport and turbulence processes.

\section{THEORY}

\section{Flow and Turbulence}

The conservation expressions for all of the variables are written in the parabolic form (Favre-averaged), for an axi-symmetric flame. A $x-\varepsilon$ turbulence model and soot formation schemes are incorporated into the model. The details of the mathematical formulation can be found elsewhere [7-9]. This model formulation has been thoroughly tested and validated using pool-like gas flames of propane [8] and methane [9]. The model provides good predictions of the centerline temperature, velocity and species distributions, the air entrainment behavior, and the radiative and convective feedback fluxes [8,9] for these pool-like gas flames. However, the radial expansion of the flame was underestimated, particularly near the flame base. This apparently arises because of the parabolic flow assumption. The lateral pressure gradient is known to cause an elliptic effect near the flame base. Our more recent work clearly indicates this behavior [9].

The initial conditions for $\kappa$ and $\varepsilon$ in the $\kappa-\varepsilon$ model were introduced at the burner exit by employing the relations, $\kappa_{0}=\alpha_{k} U_{0}^{2}$ and $\varepsilon_{0}=\alpha_{\varepsilon}$ $\kappa^{3 / 2} / r$, where $r$ is the pool radius and $\alpha_{k}=10$ and $\alpha_{\varepsilon}=1$. These values were obtained by optimizing the initial conditions for best agreement with the experimental propane pool-like gas flame behavior, and leaving them unchanged for this work. It is possible that this approach might compensate for the lack of elliptic treatment near the flame base, and improve the near field predictions.

\section{Combustion Rate}

The chemical kinetics are assumed to be infinitely fast. However, the microscale processes responsible for the turbulence dissipation and molecular mixing in the turbulent field are typically intermittent and certainly not infinitely fast. The details of this model can be found elsewhere $[7-9,11]$. Within this model, the overall reaction rate is given by the expression,

$R_{f u}=\left[\dot{m} /\left(1-r^{*}\right)\right] C_{\text {min }}\left(\mathrm{kg} / \mathrm{m}^{3} \mathbf{s}\right)$

where $C_{\text {min }}$ is the smaller of $\mathrm{C}_{f u}$ and $\mathrm{C}_{02} / \mathrm{r}_{\mathrm{fu}}$. Here, $\mathrm{C}_{f u}$ and $\mathrm{C}_{02}$ are the concentrations of fuel and oxygen respectively, and $r_{f u}$ is the stoichiometric oxygen requirement for one $\mathrm{kg}$ of fuel. The quantity $\mathrm{m}$ is defined in terms of $\kappa$ and $\varepsilon$ and the kinematic isotropic viscosity $v$, and the fraction of the fluid contained within the fine structures $r *[7-9,11]$.

\section{Radiation}


The four flux model, in terms of radiation flux sums $F_{2}$ and $F_{y}$, in the axial and radial directions, is given as $[7-9,12]$ :

$\mathrm{d} / \mathrm{dz} \quad\left[\begin{array}{lll}\Gamma_{\mathrm{z}} & \mathrm{dF} & \mathrm{d} / \mathrm{d}_{\mathrm{z}}\end{array}\right]=\mathrm{K} \quad\left(\mathrm{F}_{\mathrm{z}}-\mathrm{E}\right)$

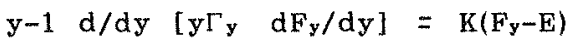

where

$\Gamma_{\mathrm{y}}=\mathrm{y} /(1+\mathrm{Ky})$ and $\Gamma_{\mathrm{z}}=1 / \mathrm{K}$

Here, $K$ is the flux absorption coefficient $\left(\mathrm{m}^{-1}\right)$ to be defined later, and $\mathrm{E}$ is the black body emissive power.

\section{Soot Formation}

The phenomenological scheme proposed by Tesner et al.[13] has been incorporated here for modeling soot formation in a turbulent field. The soot formation process depends on the formation of active radical particles. From these particles, soot particles grow. The formation rate of radical nuclei is given by :

$R_{n, f}=n_{0}+(f-g) n-g o n N\left(\operatorname{part} / m^{3} / s\right)$

where $\mathrm{N}$ is the concentration of soot particles (part/m $\mathrm{m}^{3}$ ) and $\mathrm{f}$, $g$ and go are constants. The spontaneous formation rate of radical nuclei, $n_{0}$, is expressed as:

$n_{0}=a_{0} \quad C_{\text {fu }} \quad \exp \left(-\mathbf{E} / \mathrm{RT}^{\mathrm{T}}\right)$

$\left(\right.$ part $\left./ \mathrm{m}^{3} / \mathrm{s}\right)$

where $C_{f u}$ is the concentration of fuel, $E$ is the activation energy, $T$ is the temperature, and $a_{0}$ is a constant. The soot formation rate is then expressed by the relation,

$R_{s, f}=m_{p}(a-b N) n \quad\left(\mathrm{~kg} / \mathrm{m}^{3} / \mathrm{s}\right)$

where $m_{p}$ is the mass of the soot particles (kg/part), and a and $b$ are constants.

The soot and radical nuclei are formed and burnt in the flame zone. The mean rate of nuclei and soot particle combustion are expressed respectively as follows:

$\begin{array}{lll}\mathrm{R}_{\mathrm{B}, \mathrm{c}}=\mathrm{R}_{\mathrm{fu}} \mathrm{n} / \mathrm{C}_{\mathrm{fu}} & \left(\operatorname{part} / \mathrm{m}^{3} / \mathrm{s}\right) \\ \mathrm{R}_{\mathrm{B}, \mathrm{c}}=\mathrm{R}_{\mathrm{fu}} \mathrm{C}_{\mathrm{s}} / \mathrm{C}_{\mathrm{fu}} & \left(\mathrm{kg} / \mathrm{m}^{3} / \mathrm{s}\right)\end{array}$

where $\mathrm{C}_{\mathrm{s}}$ is the soot concentration $\left(\mathrm{kg} / \mathrm{m}^{3}\right)$. The constants needed for the soot calculations are taken from Ref.11, except that the particle size was increased to $200 \mathrm{~A}$.

The absorption coefficient, $\mathrm{k}_{\mathrm{g}}$, due to the gas was calculated using a weighted sum-gray gases model as reported by Smith et al.[14]. The details are reported elsewhere [8,9]. The soot absorption coefficient is evaluated by [5]

$k_{s}=3.6 \quad C_{0} \quad f_{v} \quad T / C_{2}$ 
Table 1. Thermochemical properties of the liquid and gas phase utilized in the present calculations.

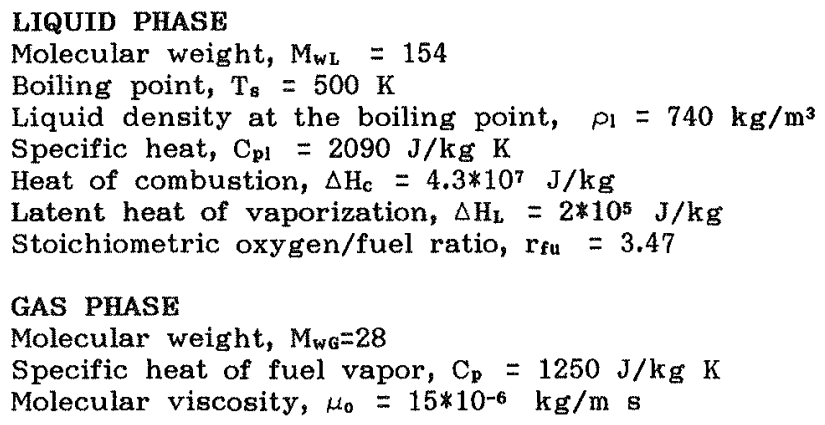

where $C_{0}$ is a constant with a value of 4.64 [5], $C_{2}$ is Planck's second constant, and $f_{v}$ is the soot volume fraction. The overall absorption coefficient $(k)$ of the soot + gas mixture was estimated by the relation [1],

$k=k_{g}+k_{s}-k_{g} k_{s}$

The flux absorption coefficient $\mathrm{K}=2 \mathrm{k}$ was assumed, implying an isotropic radiation intensity [12]. The source term of the enthalpy equation due to the axial and radial radiation fluxes is $2 \mathrm{~K}\left(\mathrm{~F}_{2}+\mathrm{F}_{\mathrm{y}}-2 \mathrm{E}\right)$. the form,

The boundary conditions for the axial radiation flux sum at $z=0$ is of

$F_{z}+p_{1} \Gamma_{2}\left(d_{2} / d z\right)=q_{1}$

where $p_{1}$ is $1 / \mathrm{K}$ and $\mathrm{q}_{1}$ is the surface radiation. The radiation was assumed to be negligible at the top of the plume.

The parabolic expressions have been numerically solved by a marching technique using a modified GENMIX code. The axial radiation flux sum, Fz, which is elliptic, was computed separately and the temperature field updated. We employed $45 \mathrm{grid}$ nodes (floating) in the radial direction. A maximum axial step size of $0.1 \%$ of the current radius of the flame was employed.

The input thermochemical properties of the fuel and gas phase are summarized in Table 1. The data are mainly taken from Ref. 15

\section{RESULTS AND DISCUSSION}

Distribution of Species, Temperature and Axial Velocity.

The distribution of various species in the flame, along the centerline for three flames of increasing pool size is shown in Figure 1. The "surface" of the stoichiometric combustion region (indicated by $S t$ in 


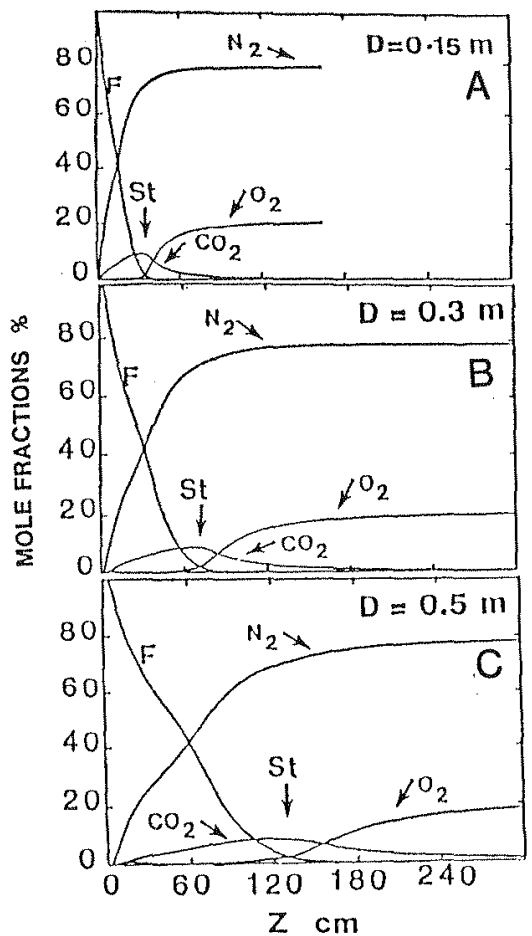

FIGURE 1. Concentration of fuel(F), oxygen, nitrogen, and products $\left(\mathrm{CO}_{2}\right.$ and $\left.\mathrm{H}_{2} \mathrm{O}\right)$, along the vertical flame axis for kerosene pool flames of indicated pool size.

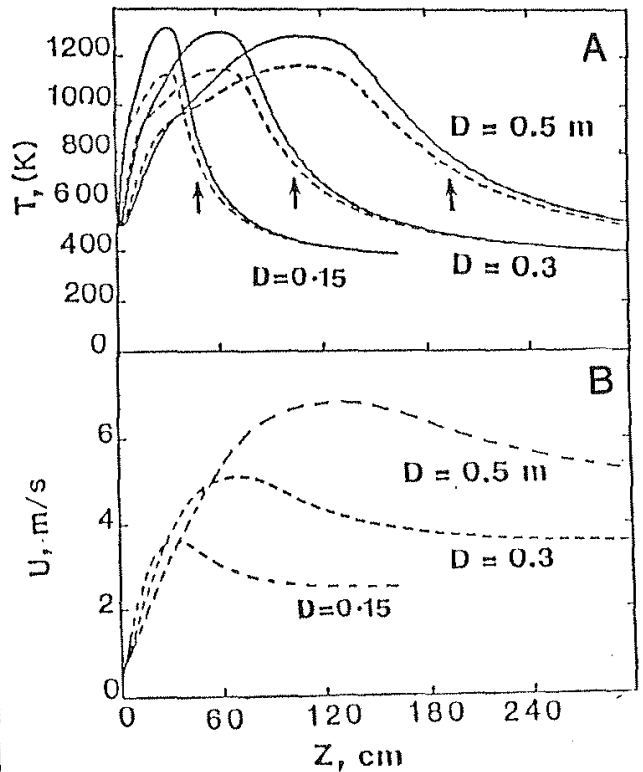

FIGURE 2. A) Distribution of mean temperature along the vertical flame axis; the dotted curves indicate temperature profiles with radiation included.

B) Axial velocity along the vertical flame axis (radiation included) for kerosene flames of the indicated pool size

Figure 1) is located at $\mathrm{Z}=40,75$ and $125 \mathrm{~cm}$ for flames of 15,30 and $50 \mathrm{~cm}$ pool diameters (i.e. $S t$ is about 2.5 times the pool diameter). This overall behavior is in agreement with the well known observations on gas flames of similar initial mass velocity or calorific output [8]. The combustion products reach a maximum at this stoichiometric point.

Axial distribution of mean temperature and axial velocities are shown in Figure $2 \mathrm{~A}$ and $\mathrm{B}$ respectively. The axial distance where the temperature is a maximum is the combustion height, $\mathrm{Z}_{c}$, of the flame. The maximum temperatures $\left(\mathrm{T}_{\mathrm{f}}\right)$ is close to $1150 \mathrm{~K}$ which is commonly observed with practical fires of kerosene or diesel fuel. The visible flame height, $Z_{v}$, is 58,105 and $212 \mathrm{~cm}$, respectively, for 15,30 and $50 \mathrm{~cm}$ pool diameter fires (shown by the upward arrows in Figure 2). These heights are determined by the axial height where the temperature drops to $700 \mathrm{~K}$. The experimental flame height of a kerosene pool fire of $15 \mathrm{~cm}$ diameter has 
been reported by Burgess et al.[16] to be $68 \mathrm{~cm}$. The overall trend is comparable with the flame height versus pool diameter curves shown in Hottels' review [17]. The axial velocity exhibits trends similar to the temperature, as shown in Figure $2 \mathrm{~B}$.

\section{Soot Concentration and Absorption-Emission Behavior}

Figure $3 \mathrm{~A}$ shows the predicted soot concentration along the flame axis. The soot that escapes downstream (smoking) is due to the combustion limitation, in this case turbulence controlled. The jet flames studied by Magnussen [11] did not show any indication of smoking. However, because of the low initial momentum of the buoyant flames in the current fires, a part of the total soot formed appears to remain unburnt. An excellent account of the mechanism of soot emission as a function of inlet fuel mass flux, turbulence, and burner diameter is given by Kent and Wagner [18].

Figure 3B shows the local absorption coefficients calculated by taking into account the fuel vapor, gaseous products, and soot absorption and emission. Here, the absorption coefficient of the fuel vapor is taken to be $1.3 \mathrm{~m}^{-1}$ based on the work of Brosmer and Tien [5]. However, the absorption-emission properties of cold fuel vapors in the vicinity of fuel surfaces need to be estimated with greater certainty. The maximum in the absorption occurs where the soot concentration is maximum, clearly suggesting the decisive effect of the soot loading on the total absorption

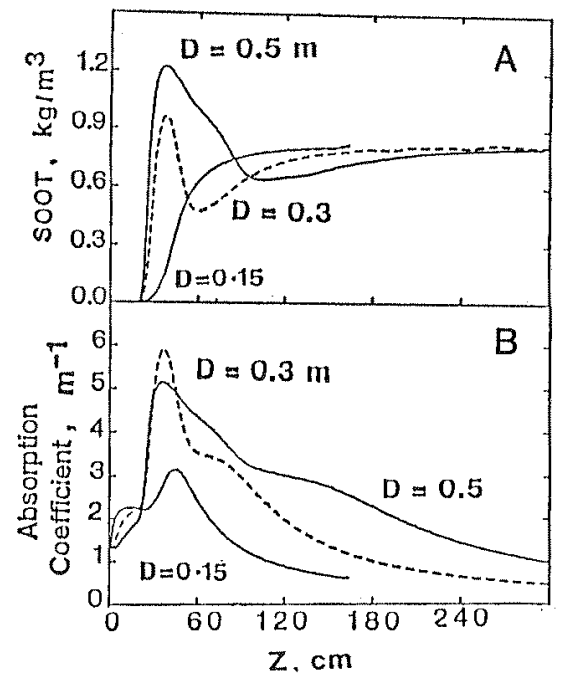

FIGURE 3. Concentration of soot (A), and local absorption coefficient (B) along the vertical flame axis for the three indicated flames.

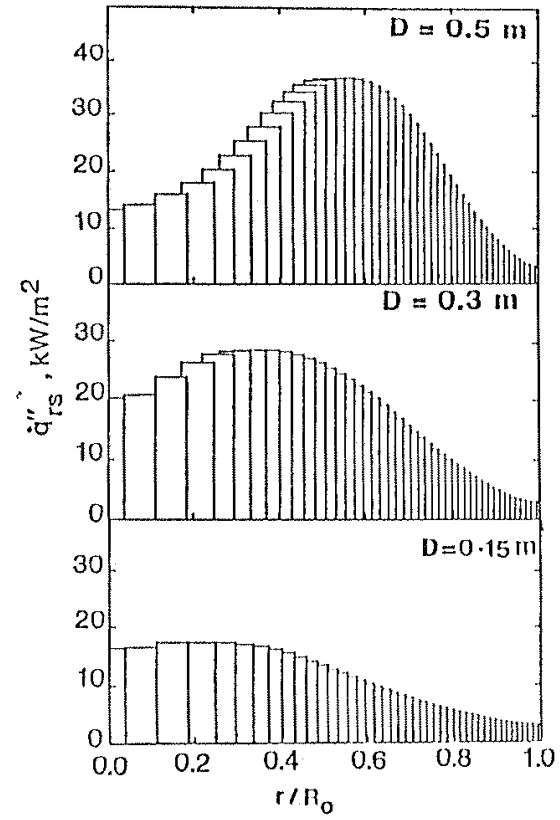

FIGURE 4. Variation of the net radiative heat flux (feedback) along the fuel surface for flames of the indicated pool size 
Table 2. Summary of flame characteristics and heat fluxes predicted by the present theory

\begin{tabular}{|c|c|c|c|}
\hline \multirow[t]{2}{*}{ Properties } & \multicolumn{3}{|c|}{ Pool diameter $(\mathrm{cm})$} \\
\hline & 15 & 30 & 50 \\
\hline $\begin{array}{l}\text { Combustion height }\left(\mathrm{Z}_{\mathbf{c}}\right), \mathrm{cm} \\
\text { calculated }\end{array}$ & 40 & 75 & 125 \\
\hline Flame height $\left(Z_{v}\right), \mathrm{cm}$ & & & \\
\hline calculated, & 58 & 105 & 212 \\
\hline Theoretical power output $\left(\mathrm{QT}_{\mathrm{T}}\right)$, $\mathrm{kW}$ & 11 & 66 & 312 \\
\hline $\begin{array}{l}\text { Completeness of combustion }\left(\mathrm{X}_{\mathrm{a}}\right) \\
\text { Radiation heat flux at the }\end{array}$ & 0.75 & 0.75 & 0.75 \\
\hline $\begin{array}{l}\text { center, calc. }\left(\dot{q}^{\prime \prime}{ }_{\mathrm{r}, 0}\right), \mathrm{kW} / \mathrm{m}^{2} \\
\text { Radiation heat flux }\end{array}$ & 16.37 & 20.18 & 13.27 \\
\hline $\begin{array}{l}\text { calc. (surface averaged) } \\
\text { (q"rs), } \mathrm{kW} / \mathrm{m}^{2} \\
\text { Convective heat feedback to }\end{array}$ & 6.02 & 13.30 & 20.34 \\
\hline fuel surface $\left(\dot{q}^{\prime \prime} \mathrm{c}\right), \mathrm{kW} / \mathrm{m}^{2}$ & 4.58 & 2.84 & 0.98 \\
\hline $\begin{array}{l}\text { Surface re-radiation }\left(\dot{q}^{\prime \prime} \mathrm{rr}\right), \mathrm{kW} / \mathrm{m}^{2} \\
\text { Gasification flux }\end{array}$ & 1.49 & 1.49 & 1.49 \\
\hline $\begin{array}{l}\text { requirement }\left(\hat{q}^{n}\right), \mathrm{kW} / \mathrm{m}^{2} \\
\text { Feedback flux, total }\end{array}$ & 9.18 & 13.77 & 22.98 \\
\hline $\begin{array}{l}\text { calculated }\left(\dot{q}^{\prime \prime} \mathrm{fa}, t\right), \quad \mathrm{kW} / \mathrm{m}^{2} \\
\text { Mass burning rate }\left(\dot{\mathrm{m}}^{\prime \prime}\right), \mathrm{g} / \mathrm{m}^{2} \mathbf{s}\end{array}$ & 9.11 & 13.65 & 19.83 \\
\hline Calculated, & 14.69 & 22.01 & 32.10 \\
\hline reported [15] & 14.80 & 22.22 & 37.07 \\
\hline Radiative fraction $\left(\mathrm{X}_{\mathrm{r}}\right)$ & 0.23 & 0.32 & 0.43 \\
\hline
\end{tabular}

$\dot{q}^{\prime \prime} r \mathrm{r}=\varepsilon_{\mathrm{s}} \sigma \mathrm{T}_{\mathrm{s}}{ }^{4}$,

where $\sigma$ is the Stefan-Boltzmann constant, $T_{\mathrm{s}}$ is the fuel surface

temperature, and $\varepsilon_{s}$ is the surface emissivity, which is taken as 0.42 for kerosene [15].

A representative analysis of the thermal radiation behavior for a pool flame of $30 \mathrm{~cm}$ diameter is given here. The radiative heat flux at the center, $\dot{q}^{\prime \prime} \mathrm{rs}, 0$, is $20.18 \mathrm{~kW} / \mathrm{m}^{2}$ for this pool. However as explained earlier, the surface averaged flux $\dot{q} " r s$ is far lower, namely $13.30 \mathrm{~kW}$. (see Table 2 for these values). The gasification flux requirement ${ }^{\mathrm{q}} \mathrm{s} \mathrm{s}$ is $13.77 \mathrm{~kW} / \mathrm{m}^{2}$; this is an experimentally measured quantity based on the fact that $\mathrm{m}^{\prime \prime}$ is measured [16]. By the energy balance equation (Eq. (11)), $\mathrm{m}$ " is calculated. Here, $\dot{\mathrm{m}}^{\prime \prime}=22.22 \mathrm{~g} / \mathrm{m}^{2} \mathrm{~s}$ is obtained for the $\mathrm{D}=30 \mathrm{~cm}$ pool fire. The reported value is 22.01 [15]. However, for larger pool sizes, the predicted feedback energy is underestimated. This might arise because some of the physical parameters (such as the combustion efficiency, emissivity etc.) are not optimized for larger scale fires.

\section{Total Radiation Output}

The total radiation output (Qext) from the flame is an important quantity which determines the extent of thermal damage by the fire. The radiative fraction, $X_{r}$, is a parameter that represents the fraction of the 
and emission processes. The magnitude of the predicted absorption coefficients are comparable to the recent experimental values reported by Markstein. [4] on propane flames. The local emissivity (not shown here) follows a similar trend. One of the significant theoretical observations of this study is the quantitative increase of the soot formation, local absorption coefficients, and emissivity of the pool flames with increasing pool size.

\section{Radiative Feedback}

The radiative heat feedback to the fuel surface is an important quantity of interest to burning rate calculations. The radial distribution of the radiative heat flux to the fuel surface, for pool fires of increasing size, are shown in Figure 4. The present observation indicates that the core properties of the flame play a dominant role in the feedback process. As the pool size increases, the flux at the center decreases (from bottom to top in this Figure). The heat flux curve has a maximum about midway along the radius. It appears that the flame envelope gets farther from the flame axis at larger fire scale, hence the cold fuel vapor and soot markedly block the radiative feedback at the center. This response has been reported recently by Brosmer and Tein [5] for a PMMA pool fire. The mass loss rate in these cases is the surface averaged quantity.

\section{Analysig of Thermal Radiation Behavior}

From the results shown above, the mass burning rate can be computed using the surface averaged radiative heat flux, $q^{\prime \prime} r$, and the energy balance for the liquid/vapor interface:

$$
\begin{aligned}
& \ddot{q} " r s+\dot{q}^{\prime \prime} c=\dot{m}^{\prime \prime}\left[\Delta H_{L}+\mathrm{C}_{p l}\left(\mathrm{~T}_{s}-\mathrm{T}_{\mathrm{a}}\right)\right]+\dot{q}^{\prime \prime}{ }_{\mathrm{rr}}+\dot{\mathrm{q}}^{\prime \prime} \lambda \\
& \text { I II III IV IV V }
\end{aligned}
$$

Here, the terms $I$ and II refer to the radiant and convective heat fluxes, respectively, to the surface of the liquid pool. The sum of these quantities is balanced by the vaporization flux requirement (term III), plus the re-radiated heat loss from the surface (term IV) and the conductive heat flux (term V) to the liquid pool. The values of the various terms indicated here have been evaluated and summarized in Table 2 for three pool sizes.

A brief account of the methods used to estimate the terms follows. The convective heat flux, $q^{\prime \prime}$, is calculated using the relation [1]:

$$
\begin{aligned}
& \dot{q}^{\prime \prime} c=\left(h / C_{p}\right)\left[\Delta H_{c}\left(X_{a}-X_{r}\right)-\left(1 / 0.232 \quad r_{f u} X_{a}\right)-\right. \\
& \left.\mathrm{C}_{\mathrm{p}}\left(\mathrm{T}_{\mathrm{s}}-\mathrm{T}_{\mathrm{a}}\right)\right] f(\mathrm{p})
\end{aligned}
$$

where $f(p)=p /\left(e^{p-1}\right)$ and $p=m^{\prime \prime} C_{p} / h$. A value of $h / C_{p}=0.01 \mathrm{~kg} / \mathrm{m}^{2} \mathrm{~s}$ was utilized along with the other properties defined in Table 1 and 2 to compute $\dot{q}^{\prime \prime} c$ for all the flames. Table 2 shows that the convective contribution decreases from 54 to $5 \%$ as the pool size increases from 15 to $50 \mathrm{~cm}$, thereby showing the importance of radiation in larger scale fires. The heat loss due to conductive heat transfer into the liquid phase is neglected in this work and the re-radiated radiation flux is computed by the relation, 
energy released by combustion which is emitted from the flame by thermal radiation $\left(X_{r}=Q_{e x t} / Q_{a}\right)$. Qext is computed from the relation,

Qext $=2 \pi \int_{0}^{Z_{p}} Y_{f l s} Q_{f l s} d z$

The term on the right hand side above represents the integral of the radiation loss from the lateral surface. Here $\mathrm{Y}_{\mathrm{fls}}$ and Qfls are the lateral coordinate and heat output at the flame surface respectively. The calculations give a value of $X_{r}=0.23,0.32$, and 0.43 for the 15,30 and 50 $\mathrm{cm}$ pool flames, which are comparable to those generally reported for open pool fires [15].

\section{CONCLUSIONS}

The pool fire characteristics of kerosene with moderate to large pool size have been investigated. The overall behavior of the predicted flame lengths and flame temperatures are reasonably close to experimental values.

The predicted soot formation behavior indicates that unlike in high initial momentum jet flames, the present fires exhibit a significant smoking tendency at the flame tip. This behavior in turn effects the radiative heat transfer. The important observation, which is consistent with previous experiment data on pool fires, is that the tendency to soot increases with pool size.

A comprehensive account of the role of thermal radiation in pool fires is described by a non-homogeneous, non-isothermal radiation model. This study provides some basic understanding of the heat transfer behavior in practical pool fires of kerosene, aspects which are beyond the scope of zone models. Considerable radiation energy blockage by the cold fuel vapor and soot formed in fires of larger size gives rise to a significantly variable heat flux distribution at the fuel surface which in turn yields a non-uniform mass burning rate.

\section{ACKNOWLEDGEMENT}

K.C.Adiga and D.E.Ramaker acknowledge the partial support of this work by the Naval Research Laboratory.

\section{REFERENCES}

1. De Ris, J., "Fire Radiation- A Review," Seventeenth Symposium (International) on Combustion, The Combustion Institute, Pittsburgh, pp. $1003-1016,1978$.

2. Modak, A.T.," Thermal Radiation from Pool Fires," Combustion and Flame $29: 117-192,1977$.

3. Markstein, G.H., "Radiative Properties of Plastic Fires," Seventeenth Symposium (International) on Combustion, The Combustion Institute, Pittsburgh, pp. 1053-1062, 1979. 
4. Markstein, G.H., " Measurement on Gaseous-Fuel Pool Fires with a Fibre Optic Absorption Probe," Combustion Science and Technology 39 : $215-233,1984$.

5. Brosmer, M.A., and Tien, C.L., "Radiative Energy Blockage in Large Pool Fires," Combustion Science and Technology $51: 21-37,1987$.

6. Buckius, B.O and Tein, C.L., "Infrared Flame Radiation," Int. J. Heat and Mass Transfer 20:93-106, 1980.

7. Adiga, K.C., Ramaker, D.E., Tatem, P.A., and Williams, F.W.," Numerical Modeling of Freely Burning Pool Fires," International Meeting of Fire Research and Test Centers, ITSEMAP/MAPRE, Avila, Spain, Vol.1, pp. 83-109, 1986.

8. Adiga, K.C., Ramaker, D.E., Tatem, P.A., and Williams, F.W., "Modeling of Turbulent Buoyant Pool-Like Gas Flames Including Radiative Heat Transfer," submitted to Combustion Science Technology, 1988.

9. Adiga, K.C., Ramaker, D.E., Tatem, P.A., and Williams, F.W.," Study of Thermal Radiation and Numerical Predictions for a Simulated Methane Fire," submitted to Combustion Science and Technology, 1988.

10. Adiga, K.C., Ramaker, D.E., Tatem, P.A., and Williams, F.W., unpublished results.

11. Magnussen, B.F., "Modeling of Reaction Processes in Turbulent Flames with Emphasis on Soot Formation amd Combustion," in Particulate Carbon: Formation During Combustion, ed. D.Siegla and G.W.Smith, pp. 321-341, Plenum Press, New York, 1981.

12. Gosman, A.D., and Lockwood, F.C., "Incorporation of a Flux Model for Radiation into a Finite Difference Procedure for Furnace Calculations," Fourteenth Symposium (International) on Combustion, The Combustion Institute, Pittsburgh, pp. $661-671,1975$.

13. Tesner, P.A., Snegiriova, T.D, and Knorre, V.G." Kinetics of Dispersed Carbon Formation," Combustion and Flame $17: 253-260,1971$.

14. Smith, T.F., Shen, Z.F., and Friedman, J.N.," Evaluation of Coefficients for the Sum of Gray Gases Model," J. Heat Transfer 104 : 602-608, 1982.

15. Ndubizu, C.C., Ramaker, D.E., Tatem, P.A., and Williams, F.W. "A Model of Freely Burning Pool Fires," Combustion Science and Technology 34 : 233-247, 1983.

16. Burgess, D.S., Grumer,J., and Wolfhard, H.S.," Burning Rates of Liquid Fuels in Large and Small Open Trays," in The Use of Models in Fire Research, ed. W.G.Berl, Publication 786, National Academy of Science, NRC Washington, D.C, 1961.

17. Hottel, H.C., " Certain Laws Governing Diffusive Burning of Liquids-A Review," Fire Res. Abs. Rev. 1:41-44, 1959.

18. Kent, J.H., and Wagner, H.G.," Why Do Diffusion Flames Emit Smoke?," Combustion Science and Technology, $41: 245-269,1984$. 